\title{
Respiratory physicians' awareness and referral of pulmonary rehabilitation in China: a cross-sectional study
}

\author{
Shengyu Hao ${ }^{1,2 \#}$, Liang Xie ${ }^{1,2 \#}$, Houhui Wang ${ }^{4 \#}$, Qinhan Wu ${ }^{1,2}$, Pan Jiang ${ }^{1,2}$, Chengyao Guo ${ }^{3}$, Weiping Hu ${ }^{1,2}$, \\ Guiling Xiang ${ }^{1,2}$, Zilong Liu ${ }^{1,2}$, Jie Liu ${ }^{1,2}$, Shanqun $\mathrm{Li}^{1,2}$ \\ ${ }^{1}$ Department of Pulmonary Medicine, Zhongshan Hospital, Fudan University, Shanghai, China; ${ }^{2}$ Clinical Center for Sleep Breathing Disorder and \\ Snoring, Zhongshan Hospital, Fudan University, Shanghai, China; ${ }^{3}$ Department of Nursing, Zhongshan Hospital, Fudan University, Shanghai, \\ China; ${ }^{4}$ Department of Respiratory and Critical Care, People's Hospital of Juxian, Rizhao, China \\ Contributions: (I) Conception and design: S Hao, L Xie; (II) Administrative support: P Jiang, L Xie, G Xiang; (III) Provision of study materials or \\ patients: Z Liu, Q Wu, W Hu; (IV) Collection and assembly of data: S Hao, Z Liu; (V) Data analysis and interpretation: Q Wu, H Wang, J Liu, S Li; \\ (VI) Manuscript writing: All authors; (VII) Final approval of manuscript: All authors. \\ \#These authors contributed equally to this work. \\ Correspondence to: Shanqun Li; Jie Liu. Department of Pulmonary Medicine, Clinical Center for Sleep Breathing Disorder and Snoring, Zhongshan \\ Hospital, Fudan University, 180 Fenglin Road, Shanghai 200032, China. Email: li.shanqun@zs-hospital.sh.cn; liu.jie@zs-hospital.sh.cn.
}

Background: Pulmonary rehabilitation (PR) has demonstrated physiological, symptom reducing, psychosocial, and health care savings benefits in multiple outcome areas for patients with chronic respiratory diseases. Physicians' PR awareness and PR referral practices are key in PR promotion. However, PR awareness and referral among respiratory physicians in China have rarely been studied. This study aims to explore respiratory physicians' perceptions towards PR and assess the referral of PR in China.

Methods: A self-administered questionnaire was distributed via WeChat and emails to respiratory physicians in hospitals to assess their attitudes toward and knowledge of PR and identify treatment barriers. The study was conducted from June through October 2019.

Results: As reported in the 520 questionnaires collected through October 2019 most respondents had heard about PR, and many had knowledge of PR practice, but relatively few had referred patients to PR before having responded to the survey. Education, region of practice, and duration of practice are significant factors that influenced the participating respiratory physicians' awareness of PR. The percentage of referral was influenced by physicians' education, region, and duration of practice. The absence of PR facilities was the main barrier to respiratory physicians' referral of patients to PR.

Conclusions: Chinese respiratory physicians' awareness of PR and referral to PR remain insufficient to support the delivery of PR to patients with chronic respiratory diseases. PR training for respiratory physicians and building PR centers are necessary to remedy these conditions.

Keywords: Pulmonary rehabilitation (PR); awareness; physician referral practices; respiratory physicians

Submitted Aug 02, 2020. Accepted for publication Jun 22, 2021.

doi: $10.21037 /$ jtd-20-2587

View this article at: https://dx.doi.org/10.21037/jtd-20-2587

\section{Introduction}

Chronic obstructive pulmonary disease (COPD) is a common respiratory disease with high morbidity and mortality found in China and worldwide. Pulmonary rehabilitation (PR) has demonstrated physiological, symptom reducing, psychosocial, and health care savings benefits in multiple outcome areas for patients with chronic respiratory diseases (1). Furthermore, it has been used in the treatment and management of patients with COPD since the 1990s. As such, it should be a standard of care applied alongside other well-established treatments for 
COPD patients such as pharmacotherapy, supplemental oxygen, and noninvasive ventilation. Yet, PR remains grossly underutilized worldwide $(2,3)$. In China, a reported $27.4 \%$ of Chinese hospitals have administered PR to patients (4). However, the actual percentage may be lower as $\mathrm{PR}$ is frequently absent from the integrated care of COPD patients and is often inaccessible to such patients. Reasons PR is not accessible to COPD patients are complex and involve the healthcare system, health care providers, and patient-related factors. One major contributory factor is the lack of physician referral, which may be due to low PR awareness/knowledge (5).

In recent years, several evidence-based guidelines have been published to assist clinicians in $\mathrm{PR}$ practice and standardize the management of PR (1). A previous study investigating $\mathrm{PR}$ in China reported low PR performance and limited PR knowledge among physicians in China (4). However, at present, the details of the factors that influence Chinese respiratory physicians' PR awareness and PR referral practice in have rarely been studied.

Due to Chinese ethnic features, medical insurance issues, socioeconomic factors, and the community health situation faced by general practitioners, the status of PR in China is quite different than in other countries. Furthermore, respiratory physicians are the first point of diagnosis and treatment for COPD patients. The referral and treatment provided by respiratory physicians are important to longterm condition management for COPD patients. To address this situation and to provide information for the future development of PR, we conducted a nationwide survey of respiratory physicians' awareness of $\mathrm{PR}$, referral to $\mathrm{PR}$, and obstacles to referral.

We present the following article in accordance with the STROBE reporting checklist (available at https://dx.doi. org/10.21037/jtd-20-2587).

\section{Methods}

\section{Study}

The study was conducted from June 2019 to October 2019. A self-administered questionnaire was developed according to the practice guidelines and other literature on PR $(1,6)$ and was distributed to physicians in hospital via WeChat and email. Association of respiratory physicians and their subspecialty groups in different provinces agreed to internally distribute the link or email to respiratory physicians.

\section{Participants}

The participants were a convenience sample of respiratory physicians working in hospitals from different provinces. Chinese hospitals are classified at three levels and hospitals from all levels were included in the study. Level 1 community hospitals have only the most basic facilities and very limited inpatient capacity; Level 2 secondary hospitals have at least 100 inpatient beds and provide acute medical care and preventative care services to populations of at least 100,000; and Level 3 tertiary hospitals are major tertiary referral centers in the provincial capitals and major cities $(7,8)$. Northeast, east, middle and west regions of China were classified by economic status. Participants' education levels were classified as less than a college degree, college degree, postgraduate degree, and doctoral and post-doctoral degree (9). Doctors' PR awareness and PR referral practices were assessed through a cross-sectional questionnaire survey.

\section{Questionnaire}

There was no validated questionnaire on this aspect suitable for use. Thus, a questionnaire was developed for this study. It was designed by the author in collaboration with a professor of PR at the Shanghai Institute of Rehabilitation at Zhongshan Hospital in Shanghai. The initial draft was critiqued by an expert panel comprising two respiratory physicians, two health care professionals, and a statistician. Each question was evaluated by the panel as either essential, useful, or irrelevant to achieving the study objectives. The accuracy and clarity of the questionnaire was also commented on and improved by the expert panel. It was finalized after collecting all the comments from the expert panel. The final questionnaire passed the appraisal of two experts in each corresponding field.

The final questionnaire (Appendix 1) included a brief introduction to PR, followed by 20 questions into three sections, interviewees' demographic information, attitudes toward PR, and PR technique. Participants provided their responses voluntarily and under the condition of anonymity, and they received no compensation.

\section{Statistical analysis}

Study data were collected and managed using the WenJuan App available from www.wenjuan.com (10). The app was 
Table 1 Characteristics of the survey respondents n (\%)

\begin{tabular}{|c|c|}
\hline Characteristic & $n=520$ \\
\hline Age, mean \pm SD [range] & $38.13 \pm 8.12[21-61]$ \\
\hline Gender, male (\%) & $204(38.78)$ \\
\hline \multicolumn{2}{|l|}{ Region (\%) } \\
\hline East & $375(72.12)$ \\
\hline Middle & $48(9.23)$ \\
\hline North east & $45(8.65)$ \\
\hline West & $52(10.00)$ \\
\hline \multicolumn{2}{|l|}{ Level of hospital (\%) } \\
\hline Tertiary hospital & $286(54.37)$ \\
\hline Secondary hospital & $233(44.30)$ \\
\hline Community hospital & $7(1.33)$ \\
\hline \multicolumn{2}{|l|}{ Education (\%) } \\
\hline Under college degree & $10(1.92)$ \\
\hline College degree & $244(46.92)$ \\
\hline Postgraduate degree & $229(44.04)$ \\
\hline Doctoral and post-doctoral degree & $37(7.12)$ \\
\hline \multicolumn{2}{|l|}{ Professional title (\%) } \\
\hline Resident physician & $121(23.27)$ \\
\hline Attending physician & $219(42.12)$ \\
\hline Associated chief physician & $101(19.42)$ \\
\hline Chief physician & 79 (15.19) \\
\hline \multicolumn{2}{|l|}{ Duration of practice (years) (\%) } \\
\hline$<5$ & $143(27.50)$ \\
\hline $5 \leq-<10$ & $113(21.73)$ \\
\hline $10 \leq-<15$ & $107(20.58)$ \\
\hline$\geq 15$ & $157(30.19)$ \\
\hline
\end{tabular}

SD, standard deviation.

used to manage study data and perform the descriptive analysis. The data were also analyzed using Microsoft Excel and SPSS software. Continuous data are presented as the mean \pm SD and analyzed by ANOVA. Univariate analysis and multivariate logistic regression analysis were employed to identify the impact of various factors on physicians' awareness of PR and referral to PR. Odds ratios (ORs) and 95\% confidence intervals (CIs) were calculated, and a $\mathrm{P}$ value less than 0.05 was considered statistically significant.

\section{Ethical statement}

The study was conducted in accordance with the Declaration of Helsinki (as revised in 2013). The study was approved by the ethics committees of Zhongshan Hospital affiliated to Fudan University, Shanghai, China (No. B2018-216).

\section{Results}

\section{Respondent characteristics}

Through Oct 2019, 520 questionnaires were received out of the 612 distributed, with an effective rate of $85 \%$. Respondents were from 126 hospital in 15 of China's 34 provinces and from four different regions that are classified by economic status. Participants comprised 317 (60.96\%) females and 203 (39.04\%) males with an average age of $38.20 \pm 8.05$ years (age range, 21-61 years). Most respiratory physicians were associated with tertiary hospitals $(283 / 520,54.42 \%)$. More than half of the physicians were qualified with postgraduate degrees or above and almost half had worked in respiratory care for over 10 years (Table 1).

\section{PR awareness}

Most of the physicians, 508 (97.69\%), had heard of PR before the survey, and $84 \%$ (442/529) had sufficient awareness or understanding of PR to provide their patients with information or guidance. Approaches to learning PR included learning by themselves (65.07\%), attending an academic conference $(60.27 \%)$, lectures at the hospital or in committees (48.37\%), and through continuing medical education (48.18\%). However, only $11.71 \%$ of respiratory physicians had taken advantage of PR training (Figure 1).

Results of univariate analysis indicate that significant factors $(\mathrm{P}<0.05)$ that influenced physicians' $\mathrm{PR}$ awareness included age, educational background, practice region, professional title, and number of years working in respiratory care. Multivariate logistic regression analysis confirmed that physicians with higher education $(\mathrm{OR}=5.33,95 \% \mathrm{CI}: 1.08-26.33, \mathrm{P}<0.05)$ and more years of practice (OR $=9.84,95 \%$ CI: $2.84-34.09$, $\mathrm{P}<0.001)$ were more likely to understand OR. Conversely, stepwise analysis revealed that physicians in the northeast had lower PR awareness than physicians in other regions (OR $=0.44,95 \%$ CI: 0.19-1.03, P=0.046) (Figure 2, Table 2).

\section{PR referral}

Of the participating physicians, 355 (68.27\%) reported 


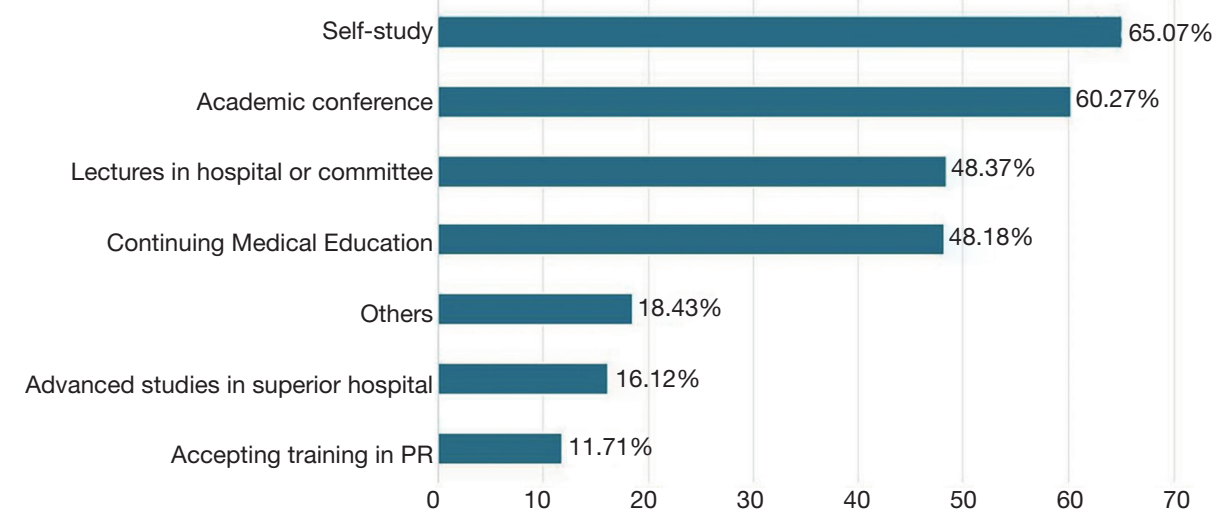

Figure 1 Percentage of PR learning approach. PR, pulmonary rehabilitation.

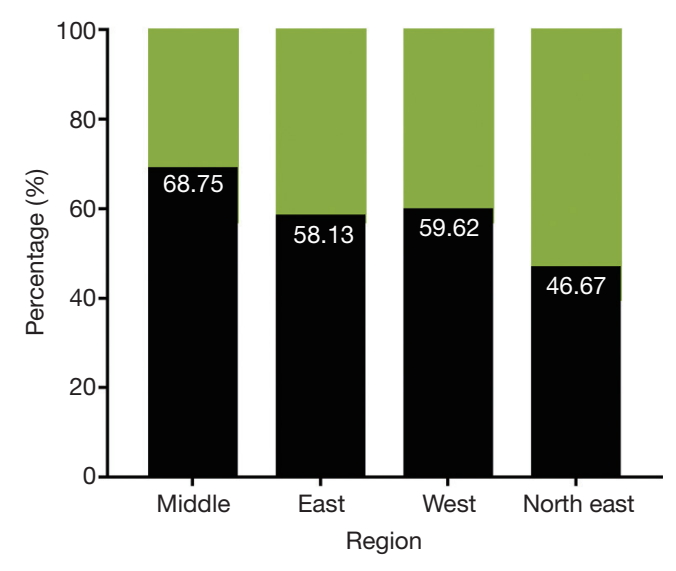

Awareness of PR No awareness of PR

Figure 2 Physicians' awareness of pulmonary rehabilitation in different regions. PR, pulmonary rehabilitation.

having provided PR referrals to patients before the study. Univariate analysis results indicated that significant factors affecting PR referral included physician age, educational background, geographic region, professional title, and duration of practice. The multivariate logistic regression analysis confirmed that physicians with higher education ( $\mathrm{OR}=5.36,95 \% \mathrm{CI}: 1.12-25.73, \mathrm{P}<0.05)$, a longer duration of practice $(\mathrm{OR}=2.61,95 \% \mathrm{CI}: 1.30-5.25, \mathrm{P}<0.001)$, in the east and middle regions ( $\mathrm{OR}=4.18,95 \% \mathrm{CI}: 1.90-9.23$, $\mathrm{P}<0.001$ ) were more likely to provide PR referral (Table 3, Figure 3). Major barriers to PR application included absence of PR institution (43.65\%), absence of PR facility or equipment $(24.23 \%)$, clinical work overload $(7.12 \%)$, limited PR knowledge (6.92\%), poor doctor-patient relationship (1.35\%) and other reasons (16.73\%) (Figure 4).

\section{Discussion}

To the best of our knowledge, this is the first study to survey Chinese respiratory physicians on their current PR awareness and practices, and our findings provide some information about PR in China. First, our data indicate that almost all respiratory physicians had heard of PR; however, only about half of them had provided PR referrals. Second, education background, duration of practice, and geographical region were the factors associated with PR awareness and referral. Thirdly, self-study was the main access to PR knowledge, and the absence of PR infrastructure was the major barrier to providing $\mathrm{PR}$ referrals reported in the survey.

COPD is the third most prevalent chronic disease in China, with $8.6 \%$ of the Chinese population suffering from it. With a rapidly aging population, high cigarette smoking prevalence, and heavy air pollution, the burden of COPD is anticipated to continue increasing in China. PR has been known to China since 1984, and the committee of PR in China was established in 2017; since then, physicians have gradually realized the importance of PR for COPD patients. Few studies have been conducted to explore the PR situation in China. Only a single national survey on PR has been conducted in China; it was carried out from March 2, 2017 through March 17, 2017 among 921 physicians. Some $51.5 \%$ of physicians reported a PR program at their hospitals; however, the survey did not exclude physicians from the same hospital, and so that conclusion may be inaccurate.

Patients will not receive $\mathrm{PR}$ without a referral, and referral is unlikely to occur unless the healthcare professionals who treat COPD patients are aware of the 
Table 2 Multivariate analysis of the factors associated with PR awareness

\begin{tabular}{|c|c|c|c|}
\hline Variable & $P$ value & OR & $95 \% \mathrm{Cl}$ \\
\hline \multicolumn{4}{|l|}{ Gender, male (\%) } \\
\hline \multicolumn{4}{|l|}{ Male } \\
\hline Female & 0.66 & 0.88 & $0.50-1.55$ \\
\hline \multicolumn{4}{|l|}{ Under college degree } \\
\hline College degree & 0.09 & 3.78 & $0.80-17.81$ \\
\hline Postgraduate degree & $0.04^{*}$ & 5.33 & $1.08-26.33$ \\
\hline Doctoral and post-doctoral degree & $0.048^{*}$ & 9.01 & $1.02-79.27$ \\
\hline \multicolumn{4}{|l|}{ East } \\
\hline Middle & 0.08 & 3.06 & $0.89-10.55$ \\
\hline North east & $0.05^{\star}$ & 0.44 & $0.19-1.03$ \\
\hline West & 0.93 & 0.96 & $0.43-2.16$ \\
\hline \multicolumn{4}{|l|}{ Level of hospital } \\
\hline \multicolumn{4}{|l|}{ Community hospital } \\
\hline Secondary hospital & 0.85 & 1.23 & $0.15-10.18$ \\
\hline Tertiary hospital & 0.78 & 1.35 & $0.16-11.54$ \\
\hline \multicolumn{4}{|l|}{ Professional title } \\
\hline \multicolumn{4}{|l|}{ Duration of practice (years) } \\
\hline \multicolumn{4}{|l|}{$<5$} \\
\hline $5-<10$ & 0.09 & 1.85 & $0.90-3.77$ \\
\hline $10-<15$ & $0.00^{\star \star}$ & 4.10 & $1.65-10.19$ \\
\hline$\geq 15$ & $0.00^{\star *}$ & 9.84 & $2.84-34.09$ \\
\hline
\end{tabular}

${ }^{*} \mathrm{P}<0.05 ;{ }^{*} \mathrm{P}<0.05$. $\mathrm{PR}$, pulmonary rehabilitation; OR, odds ratio; $\mathrm{Cl}$, confidence interval.

existence of PR and have knowledge of its benefits (11). Our investigation found high levels of PR awareness among respiratory physicians, and most of them had heard of and understood PR before this survey. Physicians with higher educational background and more years of practice in respiratory care had a better awareness of PR, which were expected. In our study, geographical region was an important factor in physician awareness of PR. As noted above, physicians in northeast China had poorer PR awareness and referral practice than those in other regions. The significant differences between physicians in different regions may be related to the differences in the economy, frequency of information communication, and the uneven distribution of medical resources. Northwest China is less 
Table 3 Multivariate analysis of the factors associated with PR referral

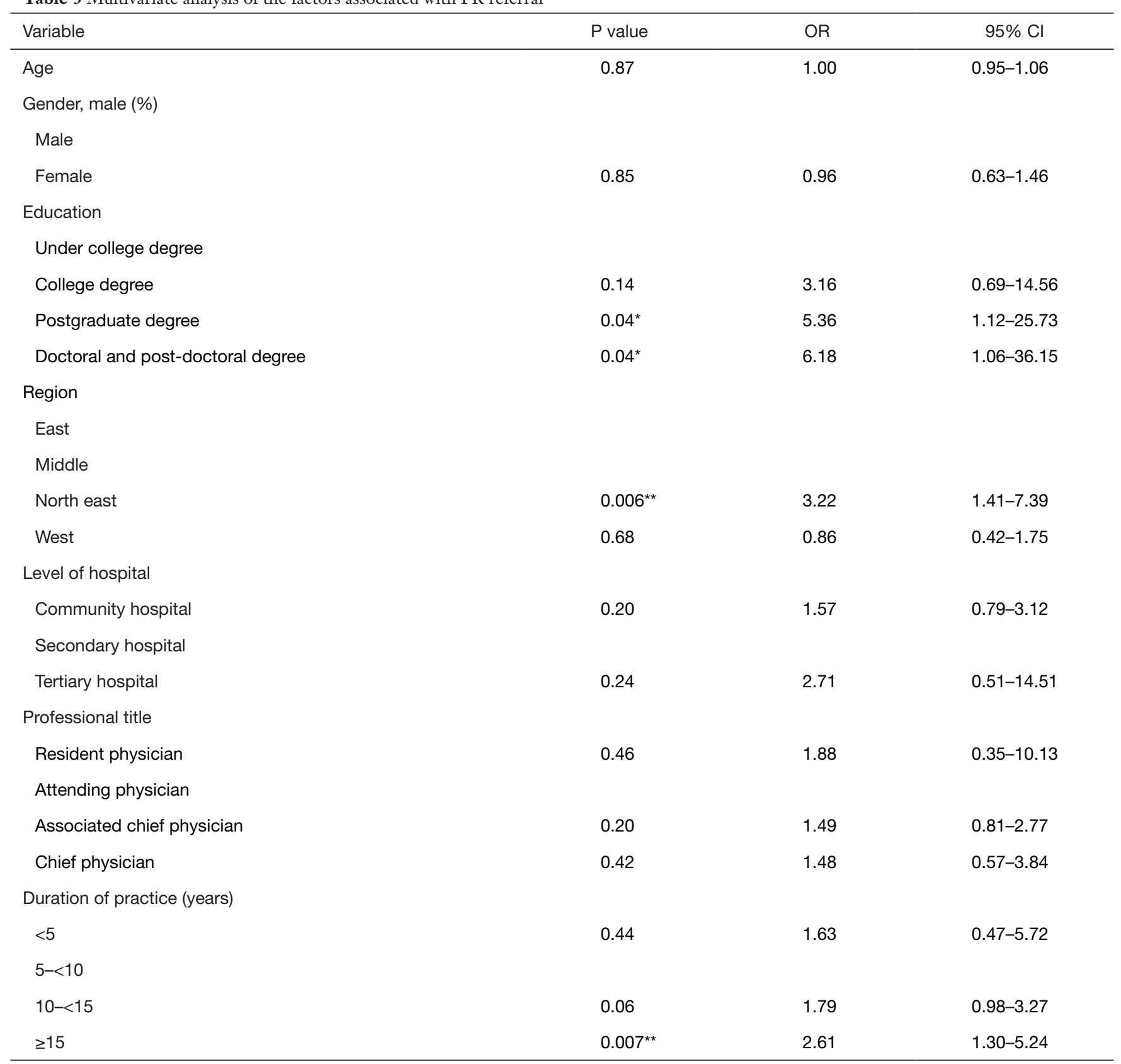

${ }^{*} \mathrm{P}<0.05$; ${ }^{* \star} \mathrm{P}<0.05$. $\mathrm{PR}$, pulmonary rehabilitation; $\mathrm{OR}$, odds ratio; $\mathrm{Cl}$, confidence interval.

developed than other areas. It is characterized by limited medical resources and a slower spread of new knowledge and technology.

Hospital level did not influence physicians' PR awareness in our study. Doctors from Level 1 community hospitals constituted only $1.34 \%$ of participants. Furthermore, $98.08 \%$ of the surveyed physicians had bachelors or postdoctoral degrees. Thus, we speculate that the actual level of awareness is lower and the problem more serious than suggested by our results. It is especially important to note that patients in other countries mainly access PR through physicians in primary hospitals and community hospitals (11); Chinese patients place more trust in the advice and services of higher-level hospitals (7). Patient 
acceptance of PR and compliance with PR may be higher if they receive PR referrals from doctors in higher level hospitals. Thus, survey responses from the physicians from tertiary and secondary hospitals were also meaningful.

In United States (12), Canada (13), Australia (5), and New Zealand (14), lack of education and opportunities to learn about PR are the main barriers to physicians improved PR awareness and knowledge. In the present study, self-learning was the main approach to PR reported, and receiving PR training was the least common approach. Some postgraduate training is available but is not mandatory and is not standardized. This indicates a clear need for enhanced and more standardized exposure to PR among respiratory physicians.

Despite the broad base of evidence and COPD guidelines recommending $\mathrm{PR}$, it is still grossly underutilized in the

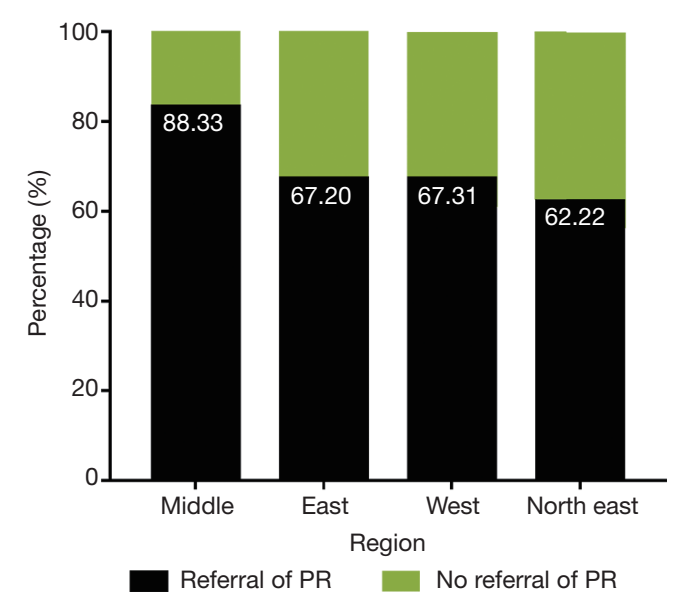

Figure 3 Physicians' referral of pulmonary rehabilitation in different regions. PR, pulmonary rehabilitation. real world $(3,15)$. In England and Wales, the prevalence of COPD patients eligible for PR was estimated at 446,000 ; however, only 68,000 patients $(15 \%$ of normative need) were actually referred; of these only $69 \%$ (10\% of normative need) attended an initial assessment (16). Much of the responsibility for the non-referral of COPD patients to PR rests with healthcare professionals (17). In our study, 355 physicians $(68.27 \%$ ) provided PR referrals, but the actual patient uptake for PR was not investigated. The absence of institutions for PR programs is the main barrier to providing PR referrals, followed by the absence of $\mathrm{PR}$ facilities or PR equipment in the hospital. These problems were also stressed in other research (18). A significant increase in funding support for PR will be needed to address these issues.

This study has several limitations. The main limitation was that the survey was conducted in a non-randomized way through social media, which may have led to selection bias. Additionally, our results are based on physicians' views as reported in the questionnaire. The actual patient uptake for PR and barriers from the patients' perspective need to be further investigated.

\section{Conclusions}

The study includes the largest survey of physicians' regarding their PR awareness, PR referral practices, and barriers to providing PR referrals. The need to establish a standard procedure and protocol for PR referral should be stressed. Provider education should be carried out to increase disease awareness and to achieve affordable and effective PR in China and facilitate the global fight against COPD.

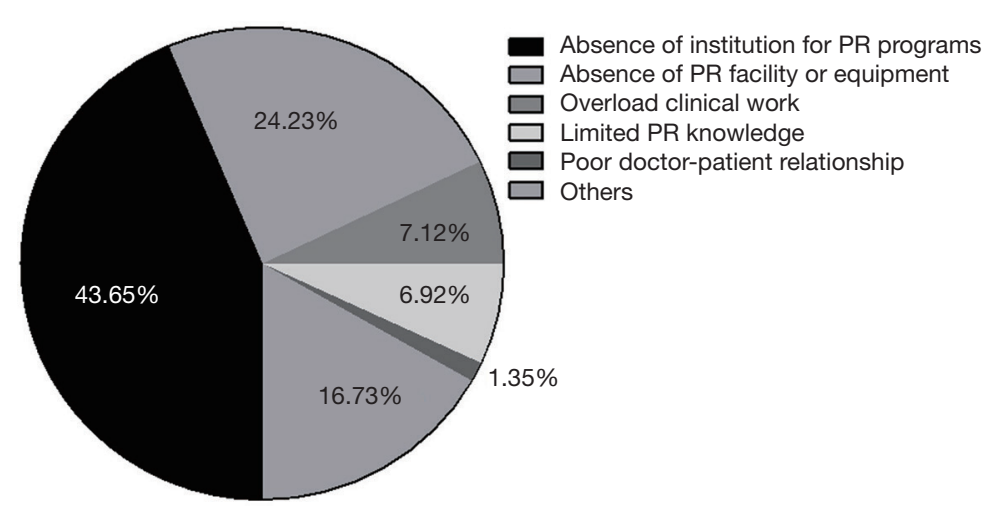

Figure 4 Physicians' view of barriers for PR referral. PR, pulmonary rehabilitation. 


\section{Acknowledgments}

We appreciate the physicians for offering the results of questionnaires, and Vikas Narang for editing the language. Funding: This work was supported by grants from the National Key Research and Development Program of China (No. 2018YFC1313600), the National Natural Science Foundation of China (No. 81570081, 81770083, 81900086) and Shanghai Rising-Star Program (19YF1407200).

\section{Footnote}

Data Sharing Statement: Available at https://dx.doi. org/10.21037/jtd-20-2587

Reporting Checklist: The authors have completed the STROBE reporting checklist. Available at https://dx.doi. org/10.21037/jtd-20-2587

Conflicts of Interest: All authors have completed the ICMJE uniform disclosure form (available at https://dx.doi. org/10.21037/jtd-20-2587). The authors have no conflicts of interest to declare.

Ethical Statement: The authors are accountable for all aspects of the work in ensuring that questions related to the accuracy or integrity of any part of the work are appropriately investigated and resolved. The study was conducted in accordance with the Declaration of Helsinki (as revised in 2013). The study was approved by the ethics committees of Zhongshan Hospital affiliated to Fudan University, Shanghai, China (No. B2018-216).

Open Access Statement: This is an Open Access article distributed in accordance with the Creative Commons Attribution-NonCommercial-NoDerivs 4.0 International License (CC BY-NC-ND 4.0), which permits the noncommercial replication and distribution of the article with the strict proviso that no changes or edits are made and the original work is properly cited (including links to both the formal publication through the relevant DOI and the license). See: https://creativecommons.org/licenses/by-nc-nd/4.0/.

\section{References}

1. Rochester CL, Vogiatzis I, Holland AE, et al. An Official American Thoracic Society/European Respiratory Society Policy Statement: Enhancing Implementation, Use, and
Delivery of Pulmonary Rehabilitation. Am J Respir Crit Care Med 2015;192:1373-86.

2. Spruit MA, Pitta F, Garvey C, et al. Differences in content and organisational aspects of pulmonary rehabilitation programmes. Eur Respir J 2014;43:1326-37.

3. Garvey C, Fullwood MD, Rigler J. Pulmonary rehabilitation exercise prescription in chronic obstructive lung disease: US survey and review of guidelines and clinical practices. J Cardiopulm Rehabil Prev 2013;33:314-22.

4. Gao LJ, Zhao HM. A nationwide online questionnaire survey of the understanding and implementation of pulmonary rehabilitation at all levels of medical institutions in China in 2017. Zhonghua Jie He He Hu Xi Za Zhi 2019;42:275-8.

5. Johnston KN, Young M, Grimmer KA, et al. Barriers to, and facilitators for, referral to pulmonary rehabilitation in COPD patients from the perspective of Australian general practitioners: a qualitative study. Prim Care Respir J 2013;22:319-24.

6. Yohannes AM, Connolly MJ. Pulmonary rehabilitation programmes in the UK: a national representative survey. Clin Rehabil 2004;18:444-9.

7. $\mathrm{LiX}, \mathrm{Lu} \mathrm{J}, \mathrm{Hu} \mathrm{S}$, et al. The primary health-care system in China. Lancet 2017;390:2584-94.

8. Song P, Jin C, Tang W. New medical education reform in China: Towards healthy China 2030. Biosci Trends 2017;11:366-9.

9. Huang J. Medical education and medical education research and development activities in modern China. Med Educ 1992;26:333-9.

10. Wenjuan App. 2013. Available online: https://www. wenjuan.com/

11. Rochester CL, Vogiatzis I, Holland AE, et al. An Official American Thoracic Society/European Respiratory Society Policy Statement: Enhancing Implementation, Use, and Delivery of Pulmonary Rehabilitation. Am J Respir Crit Care Med 2015;192:1373-86.

12. 2010 Respiratory medicine single CCT decision aid. Joint Royal Colleges of Physician Training Board. Available online: https://www.jrcptb.org.uk/documents/2010respiratory-medicine-single-cct-decision-aid-revised-2014

13. Camp PG, Hernandez P, Bourbeau J, et al. Pulmonary rehabilitation in Canada: A report from the Canadian Thoracic Society COPD Clinical Assembly. Can Respir J 2015;22:147-52.

14. Brooke ME, Spiliopoulos N, Collins M. A review of the availability and cost effectiveness of chronic obstructive 
pulmonary disease (COPD) management interventions in rural Australia and New Zealand. Rural Remote Health 2017;17:4017.

15. Hayton C, Clark A, Olive S, et al. Barriers to pulmonary rehabilitation: characteristics that predict patient attendance and adherence. Respir Med 2013;107:401-7.

16. Steiner M, Holzhauer-Barrie J, Lowe D, et al. Pulmonary rehabilitation: time to breathe better. National Chronic Obstructive Pulmonary Disease (COPD) Audit Programme: resources and organisation of pulmonary rehabilitation services in England and Wales 2015.

Cite this article as: Hao S, Xie L, Wang H, Wu Q, Jiang P, Guo C, Hu W, Xiang G, Liu Z, Liu J, Li S. Respiratory physicians' awareness and referral of pulmonary rehabilitation in China: a cross-sectional study. J Thorac Dis 2021;13(8):47534761. doi: $10.21037 /$ jtd-20-2587
National organisational audit report. London: RCP, 2015.

17. Nici L, Donner C, Wouters E, et al. American Thoracic Society/European Respiratory Society statement on pulmonary rehabilitation. Am J Respir Crit Care Med 2006;173:1390-413.

18. Collins EG, Bauldoff G, Carlin B, et al. Clinical competency guidelines for pulmonary rehabilitation professionals: position statement of the American Association of Cardiovascular and Pulmonary Rehabilitation. J Cardiopulm Rehabil Prev 2014;34:291-302. 


\section{Appendix 1}

A. Personal information:

1. Gender: $\square$ Male, $\square$ Female

2. Age:

3. Education: $\square$ Under college degree, $\square$ College degree, $\square$ Postgraduate degree, $\square$ Doctoral and post-doctor degree;

4. Professional title: $\square$ Resident physician, $\square$ Attending physician, $\square$ Associated chief physician, $\square$ Chief physician.

5. Duration of practice:

6. Hospital:

7. Province:

8. Area of China:

9. Classification of hospital: $\square$ Level 1, $\square$ Level 2, $\square$ Level 3 .

B. Awareness and referral of Lung Rehabilitation (pulmonary Rehabilitation)

10. Have you heard of pulmonary rehabilitation? $\square$ Yes $\square$ No $\square$ Not sure

11. Have you ever provided pulmonary rehabilitation referral to the patient? $\square \square$ Yes $\square \square$ No $\square \square$ Not sure

12. If your answer is "yes". Among all your patients, the percentage of patients who are recommended or introduced for pulmonary rehabilitation

13. Please mark the approximate range on the centimeter below
0 $10 \_20$ $30 \_40$ $50 \_60 \_70$ 80 90 $100 \%$

14. Have you ever explained and introduced pulmonary rehabilitation to the patient in detail? $\square \square$ Yes $\square \square$ No $\square \square$ Not sure

15. How would you describe your knowledge of pulmonary rehabilitation (respiratory rehabilitation)?

$\square$ I have never heard of pulmonary rehabilitation

$\square$ I heard of pulmonary rehabilitation, but don't understand it.

$\square$ I know about of pulmonary rehabilitation, but not enough for me to provide PR referral to patients

$\square$ I am familiar with pulmonary rehabilitation and can provide referral of PR to the patient, but I will not prescribe exercise to patients.

$\square$ I am very familiar with pulmonary rehabilitation and I will provide a prescription of PR for the patients.

16. Please rate your understanding of pulmonary rehabilitation. 0 means completely unaware, 10 means perfect score, very familiar. Your score for yourself is

17. Have you studied the theoretical knowledge of pulmonary rehabilitation? $\square$ Yes $\square \square$ No $\square \square$ Not sure

18. Learning path (multiple choice): $\square$

$\square$ self-study (check the information by yourself, watch the video)

$\square$ Hospital or community organization lectures, ppt learning (passive learning)

$\square$ have been trained in a specialized rehabilitation institution

$\square$ Other:

19. Are you willing to perform pulmonary rehabilitation on your patients? $\square \square$ Yes $\square \square$ No $\square \square$ Not sure

20. What do you think are the reasons that restrict you from providing pulmonary rehabilitation to the patients?

$\square$ The information of pulmonary rehabilitation is limited.

$\square$ The medical task is heavy, even if I know that the pulmonary rehabilitation is good, I will not introduce it to the patient 口पThe doctor-patient relationship is not good now, I don't have to ask for trouble $\square \square$ Absence of facility of equipment for patients to get pulmonary rehabilitation

$\square$ Other 